\title{
Effect of modified pomace on copper migration via riverbank soil in southwest China
}

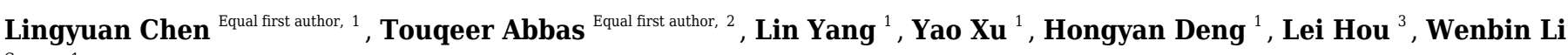 \\ Corresp. 1 \\ ${ }^{1}$ College of Environmental Science and Engineering, China West Normal University, Nanchong, China \\ ${ }^{2}$ Zhejiang Provincial Key Laboratory of Agricultural Resources and Environment, Zhejiang, Pakistan \\ 3 College of Resources \& Environment, Tibet Agricultural and Animal Husbandry University, Nyingchi, china \\ Corresponding Author: Wenbin Li \\ Email address: Iwb062@163.com
}

To explore the effects of modified pomace on copper migration via the soil on the banks of the rivers in northern Sichuan and Chongqing, fruit pomace $(P)$ and ethylene diamine tetraacetic acid (EDTA) modified $P$ (EP) were evenly added ( $1 \%$ mass ratio) to the soil samples of Guanyuan, Nanbu, Jialing, and Hechuan from the Jialing River; Mianyang and Suining from the Fu River; and Guangan and Dazhou from the Qu River. The geochemical characteristics and migration rules of copper in different amended soils were simulated by column experiment. Results showed that the permeation time of copper in each soil column was categorized as EP-amended $>$ P-amended $>$ original soil, and the permeation time of amended soil samples at different locations was jialing > Suining > Mianyang > Guangan > Dazhou > Nanbu > Guanyuan > Hechuan. Meanwhile, the average flow rate of copper in each soil column showed a reverse trend with the permeation time. Copper in exchangeable, carbonate, and iron-manganese oxide forms decreased with the increase of vertical depth in the soil column, among which the most evident decreases appeared in the carbonate-bonding form. The copper accumulation in different locations presented a trend of Jialing $>$ Suining $>$ Mianyang $>$ Guangan $>$ Dazhou $>$ Nanbu $>$ Guangyuan $>$ Hechuan, and the copper content under the same soil showed EP-amended > P-amended $>$ original soil. The copper proportion of the carbonate form was the highest in each soil sample, followed by the exchangeable form. The proportions of iron-manganese oxide and organic matter forms were relatively small. A significant correlation was observed between the cation exchange capacity and the copper content in exchangeable and carbonate forms. Moreover, total organic carbon and copper contents were negatively correlated. 
1 Effect of modified pomace on copper migration via riverbank soil in

2

3

4

5

6

\section{southwest China}

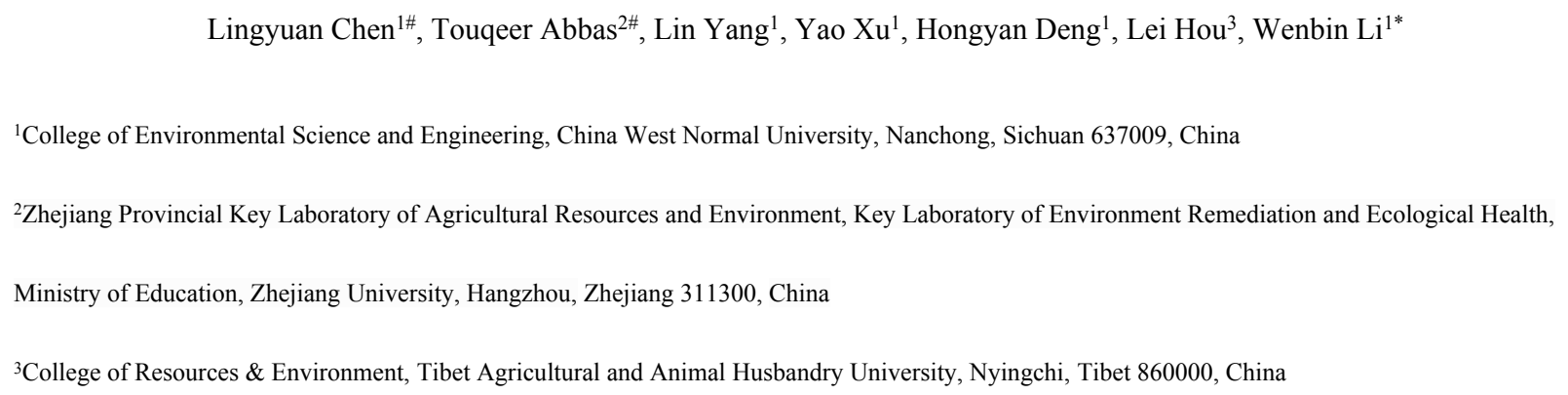

ABSTRACT

To explore the effects of modified pomace on copper migration via the soil on the banks of the rivers in northern Sichuan and Chongqing, fruit pomace (P) and ethylene diamine tetra-acetic acid (EDTA) modified P (EP) were evenly added ( $1 \%$ mass ratio) to the soil samples of Guanyuan, Nanbu, Jialing, and Hechuan from the Jialing River; Mianyang and Suining from the Fu River; and Guangan and Dazhou from the Qu River. The geochemical characteristics and migration rules of copper in different amended soils were simulated by column experiment. Results showed that the permeation time of copper in each soil column was categorized as EP-amended $>$ Pamended $>$ original soil, and the permeation time of amended soil samples at different locations was Jialing $>$ Suining $>$ Mianyang $>$ Guangan $>$ Dazhou $>$ Nanbu $>$ Guanyuan $>$ Hechuan. Meanwhile, the average flow rate of copper in each soil column showed a reverse trend with the permeation time. Copper in exchangeable, carbonate, and iron-manganese oxide forms decreased with the increase of vertical depth in the soil column, 
27

among which the most evident decreases appeared in the carbonate-bonding form. The copper accumulation in different locations presented a trend of Jialing $>$ Suining $>$ Mianyang $>$ Guangan $>$ Dazhou $>$ Nanbu $>$ Guangyuan $>$ Hechuan, and the copper content under the same soil showed EP-amended $>$ P-amended $>$ original soil. The copper proportion of the carbonate form was the highest in each soil sample, followed by the exchangeable form. The proportions of iron-manganese oxide and organic matter forms were relatively small. A significant correlation was observed between the cation exchange capacity and the copper content in exchangeable and carbonate forms. Moreover, total organic carbon and copper contents were negatively correlated.

Keywords: Copper, Modified pomace, Riverbank soil, Geochemical characteristics, Column experiment

\section{INTRODUCTION}

With the continuous innovation and development of modern industries, human society has made progress. However, the pollution threat to the environment has become increasingly serious (Pérez et al., 2006; Tahmineh et al., 2013). A large number of harmful metals (i.e., $\mathrm{Hg}, \mathrm{Cd}, \mathrm{Pb}, \mathrm{Cu}, \mathrm{Cr}$, and $\mathrm{Zn}$ ) are discharged into the soil environment (Huang et al., 2007; Bhuiyan et al., 2010), thus damaging the soil microbial community, altering the soil chemical properties, incorporating into plants, and ultimately entering the food cycle. Among these metals, the toxicity of copper pollution cannot be underestimated. Copper pollution mainly comes from natural and anthropogenic activities, and it cannot be degraded in the soil. Compared with other heavy metal elements, copper pollution is more common (Xiong et al., 2010). It not only brings great difficulties to soil remediation but also contaminates bodies of water (Fereydoun et al., 2015), which directly or indirectly poses threats to biological and human beings. In recent years, heavy metal pollution has become increasingly serious (Zhu et al., 2018; Reetu et al., 2019). Similarly, the application of livestock and poultry manure on the banks of the Jialing River, the Fu River, and the Qu River in northern Sichuan and Chongqing has caused severe copper pollution in the soil (Mohammad, 2017; Li et al., 2012). Riverbank soil is the last barrier of the river from copper pollution. Therfore, studying this soil is of great significance to determine the migration features and migration rules of copper in the bank soil to protect the river body.

Studies on the application of materials for repairing copper-contaminated soil have been widely praised (Bes \& Mench, 2008; Malandrino et al., 2011). Mao et al. (2019) found that various factors, such as ash content, 
54 fixed carbon content, specific surface area, oxygen-carbon ratio, and pore size distribution, affect the copper

55

56

57

58

59

60

61

62 adsorption capacity by wood biochar (Wang et al., 2019). Shen et al. (2017) used NaOH/KOH modified biochar (prepared by lemon residue) to adsorb copper ion and found that the adsorption rate of copper was $7.28-8.40 \%$. Thus, the influence of $\mathrm{NaOH} / \mathrm{KOH}$ modification on copper adsorption was not remarkable (the adsorption rate was $5.04 \%$ of unmodified biochar). Other researchers used $\mathrm{H}_{3} \mathrm{BO}_{3}$ (Shen et al., 2017) and $\mathrm{H}_{3} \mathrm{PO}_{4}$ (Shen \& Lei, 2016) modified lemon residue to carry out the adsorption experiment, and the copper adsorption rate reached $29.71 \%$ and $26.90 \%$, respectively. Lemon pomace contains citric acid, which can neutralize $\mathrm{NaOH} / \mathrm{KOH}$, and enhances the adsorption ability of biochar. Moreover, acid-modified material can better improve the adsorption ability to copper than alkaline-modified material. Ethylene diamine tetra-acetic acid (EDTA) is an organochemical agent and chelating agent. Previous studies have shown that EDTA has a wide range of coordination properties and can form stable chelates with almost all metal ions (Yoshinobu et al., 1997; Radanovi et al., 2004). The removal effect of EDTA on soil heavy metals is remarkably higher than that of other surfactants (Wasay et al., 1998; Zhang et al., 2013). EDTA can form a EDTA-Cu chelate with high stability (Yuan et al., 2019), which is a very favorable modifier for lemon residue modification used in copper adsorption.

Anyue City of Sichuan province enjoys the reputation of being "the hometown of Chinese lemon" and stands out in the development of the Chinese lemon industry. The lemon planting area of Anyue City was 34700 $\mathrm{hm}^{2}$ in 2018 . In addition, the fresh fruit output was $580000 \mathrm{~T}$, which accounted for more than $80 \%$ of the total area and output of the city $(L i \& Z h u, 2019)$. The products developed from lemon production include lemon oil, lemon fermented vinegar, lemon pectin, lemon beverage, lemon fermented fruit wine, and lemon tea. A large amount of waste lemon pomace residue is produced in deep processing every year (Qin et al., 2012; Shen \& Shen, 2012). The traditional treatment method of lemon pomace involves directly discarding, landfilling, or processing the product into feed, which not only wastes resources but also has a negative impact on the environment (Zhang et al., 2006; Li et al., 2011; Hao et al., 2016; Li \& Zhu, 2019). Lemon pomace residue contains numerous functional groups that can chelate with metal ions or molecules, such as the carboxyl group, hydroxyl group, thiol group, and amino group (Parajuli et al., 2008). Using lemon pomace as an adsorbent not only realizes the comprehensive utilization of lemon pomace but also absorbs the heavy metal in the soil to achieve the purpose of soil restoration. 
81

As the transition zone between land and river, riverbank soil plays an important role in the adsorption and retardation of pollutant migration into river water. With the long-term discharge of industrial and agricultural production wastes on the banks of the rivers, heavy metal pollutants in riverbank soil are accumulating, which poses a serious threat to the river water ( $\mathrm{Li}$ et al., 2020). In this study, lemon pomace and EDTA-modified lemon pomace were used to amend a riverbank soil sample. Then, the raw soil was taken as the control. The soil column model (Christian et al., 1999; Papassiopi et al., 1999; Hu et al., 2014; Sun et al., 2001) was selected to study the distribution, accumulation, migration, and geochemical characteristics of copper in the riverbank soil. The purpose of this study was to provide reference for the protection of river basins in northern Sichuan and Chongqing and to explore the benefits of fruit residual waste for the remediation of heavy-metal-contaminated soil.

\section{MATERIALS AND METHODS}

\section{Materials}

Lemon pomace (P) was collected in Anyue City, Sichuan Province, and the samping work was conducted in privately-owned land from Mr. Xie Jia. The raw P was washed with deionized water several times, dried in an oven at $60{ }^{\circ} \mathrm{C}$ to constant weight, crushed, and sieved through 40 mesh size. Then, it was accurately weighed to $50 \mathrm{~g}$ into a 1-L beaker. Afterward $250 \mathrm{~mL}$ of absolute ethyl alcohol and $250 \mathrm{~mL}$ of $0.4 \mathrm{~mol} / \mathrm{L} \mathrm{NaOH}$ solution were added. Then, the solution was stirred for 24 hours and washed again with deionized water to neutral, centrifugal filtration. Finally, it was put it into the oven for drying, and grounded through a 60-mesh sieve. After the materials were prepared, they were set aside for later use.

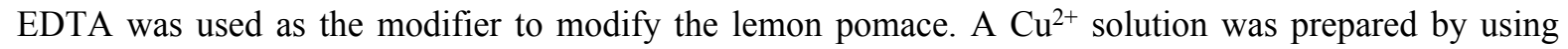
analytical reagent-grade $\mathrm{CuSO}_{4} \cdot 5 \mathrm{H}_{2} \mathrm{O}$. EDTA (analytical reagent) and $\mathrm{CuSO}_{4} \cdot 5 \mathrm{H}_{2} \mathrm{O}$ (analytical reagent) were purchased from Chengdu Kelon Chemical Reagent Factory, Chengdu City, Sichuan Province, China.

The specific process of EDTA-modified P (EP) preparation was as follows. First, $50 \mathrm{~g}$ of pretreated $\mathrm{P}$ material was accurately weighed into a 1-L beaker. Then, a 500-mL 0.5-mol/L EDTA solution was added. Next, the material was stirred evenly and put it in a constant temperature oscillator at $25^{\circ} \mathrm{C}$ for 12 hours. Then, it was washed to neutral with deionized water and centrifugally filtered. Finally, it was left in the oven for drying and grounding through a 60-mesh sieve. 
108

109

110

111

112

113

114

115

116

117

118

119

120

121

122

123

124

125

126

127

128

129

130

131

132

133

The soil samples were collected from three rivers in Sichuan and Chongqing. The sampling points (Fig. 1) from north to south were Guangyuan (GY), Nanbu (NB), Jialing (JL), and Hechuan (HC) from the Jialing River; Mianyang (MY) and Suining (SN) from the Fu River; and Guang'an (GA) and Dazhou (DZ) from the Qu River. Down by the village and within $50 \mathrm{~m}$ from the riverbank, a typical area (with same vegetation type and land use pattern) was selected, and 0-20 cm soil samples were collected via multi-point sampling. The soil samples were mixed evenly, air-dried, and then passed through a 60-mesh sieve. The physical-chemical properties of the samples are shown in Table 1.

\section{Experimental device}

Riverbank soil has low clay content and higher sand content with a large particle diameter. In addition, $\mathrm{Cu}^{2+}$ migrates faster in riverbank soil than that in agriculture soil. By experimenting with the blocking effects and lateral diffusion of $\mathrm{Cu}^{2+}$ in soil columns of various sizes, a PVC pipe (length $20 \mathrm{~cm}$, inner diameter $1.6 \mathrm{~cm}$, and outer diameter $2 \mathrm{~cm}$ ) was used to make a soil column for simulating the migration and distribution characteristics of copper. Sieve plate was placed at the inlet end and outlet end of the column (upper sieve plate prevents the water from impacting the soil sample, and the lower sieve plate prevents the soil sample from flowing down). Sand $(0.3 \mathrm{~cm})$ was filled between the upper sieve plate and the soil sample, and between the lower sieve plate and the soil sample to prevent the soil sample from blocking the micro-pores on the sieve plate. The flow rate of the $\mathrm{Cu}^{2+}$ solution was controlled by the flow meter in the pipeline. The specific schematic diagram is shown in Fig. 2 .

\section{Experimental design}

P and EP were added to the bank soil samples of GY, NB, JL, HC, MY, SN, GA, and DZ, at a mass ratio of $1 \%$. They were mixed evenly with original bank soils as contrast $(\mathrm{CK})$, thus resulting in 24 kinds of amended soil samples, namely, $\mathrm{GY}_{\mathrm{CK}}(\mathrm{GY}$ soil $), \mathrm{GY}_{\mathrm{P}}\left(\mathrm{GY}\right.$ soil + 1\%P), GY $\mathrm{EP}_{\mathrm{GY}}(\mathrm{Goil}+1 \% \mathrm{EP})$, and so on. The column experiment was conducted to simulate the migration and geochemical characteristics of copper in each amended soil sample. Each treatment was repeated three times.

\section{Experimental methods}

The amended soil samples were uniformly loaded into the soil column to maintain the same weight and 
134

135

density, with a weight of $48 \mathrm{~g}$, a density of $1.19 \mathrm{~g} / \mathrm{cm}^{3}$, and water content of $1.5-2.2 \%$. A fluid reservoir containing $500 \mathrm{mg} / \mathrm{L}$ of $\mathrm{CuSO}_{4} \cdot 5 \mathrm{H}_{2} \mathrm{O}$ was placed $1 \mathrm{~m}$ above the soil column and connected by a hose. The $\mathrm{Cu}^{2+}$ solution switch was turned on to control the natural flow rate. The $\mathrm{Cu}^{2+}$ concentration at the outlet of the soil column was measured every day at same time until the $\mathrm{Cu}^{2+}$ concentration was equal to $500 \mathrm{mg} / \mathrm{L}$. Then, the total leaching time and volume of the $\mathrm{Cu}^{2+}$ solution were determined. Next, the $\mathrm{Cu}^{2+}$ solution in the reservoir was replaced with deionized water to wash (12 hours) the residual $\mathrm{Cu}^{2+}$ solution in the soil sample pores. After the experiment, the soil column was divided into four parts: $0-5 \mathrm{~cm}, 5-10 \mathrm{~cm}, 10-15 \mathrm{~cm}$, and $15-20 \mathrm{~cm}$ from top to bottom. The soil samples of each part were air-dried and passed through a 60-mesh sieve. Then, the copper content in exchangeable, carbonate, iron-manganese oxide, and the organic matter forms of the four parts were determined (Ari \& Anne, 2005; Silveira et al., 2006; Perlatti et al., 2014).

$\mathrm{Cu}^{2+}$ contents in soil samples were determined via Hitachi Z-5000 (Japan) flame atomic absorption spectrophotometry, and background absorption was corrected through Zeeman effect. The above determination was inserted into the standard solution for analysis and quality control.

SPSS 16.0 statistical analysis software was used to process the experimental data for correlation analysis. AutoCAD2020 and SigmaPlot 10.0 software was adopted to improve data plotting.

\section{RESULTS}

\section{Copper penetration characteristics}

The results in Table 2 showed that as $\mathrm{Cu}^{2+}$ passed through the soil column, the permeation time of copper (when the $\mathrm{Cu}^{2+}$ concentrations at the inlet and outlet are identical) in each soil column was between 68 and 208 hours. For the same soil samples, the time required for copper penetration equilibrium in the soil column showed the trend of EP-amended $>$ P-amended $>$ original soil $(\mathrm{CK})$. In addition, the permeation time of EP- and Pamended soil is greater than that of CK. The average flow rate was negatively correlated with the permeation time, which showed a trend of CK > P-amended > EP-amended soil, and the average flow rate was between 9.7 and $18.9 \mathrm{~mL} / \mathrm{h}$. In general, the addition of $\mathrm{P}$ and $\mathrm{EP}$ in the soil prolonged the penetration time and reduced the penetration velocity. However, the comparative effect of the two materials showed that the adsorption performance of EP for copper ions was stronger than that of P. Given that EDTA is an acidic organic compound, it can chelate with almost all heavy metal ions to form a stable compound. Among the metal chelating agents, 
161

162

163

164

165

166

167

168

169

170

171

172

173

174

175

176

177

178

\section{9}

180

181

182

183

184

185

186

187

the chelating effect of copper is significant (Zhang et al., 2018).

For the same soil sample, the permeation time showed a higher to lower trend, i.e., $\mathrm{JL}>\mathrm{SN}>\mathrm{MY}>\mathrm{GA}>$ $\mathrm{DZ}>\mathrm{NB}>\mathrm{GY}>\mathrm{HC}$, while the average velocity was negatively correlated with the permeation time (Fig. 3). The permeation time of the $\mathrm{HC}$ soil sample to reach equilibrium was the shortest, and the average flow rate was the largest. This outcome is mainly because the $\mathrm{pH}$ value of the $\mathrm{HC}$ soil sample was acidic; the free copper in the soil was increased, and the cation exchange capacity (CEC) of HC soil was small (Arias et al., 2006), which was not conducive to the adsorption and immobilization of copper in the soil column. However, the CEC and clay content of JL soil sample was higher (Table 1). Thus, the adsorption of copper was stronger, which was conducive to the adsorption and immobilization of copper.

\section{Vertical distribution of copper}

After the penetration test, the soil columns were divided into four parts: $0-5,5-10,10-15$, and $15-20 \mathrm{~cm}$ from top to bottom. Copper in exchangeable, carbonate, and iron-manganese oxide form decreased from top to bottom, as shown in Figure 4. Among all forms of copper, the carbonate form decreased most, followed by the exchangeable and iron-manganese oxide forms. The organic matter form was the weakest (Fig. 4). The distribution curve of copper on P-amended soil was relatively concentrated, while most of the copper distribution curve was dispersed on EP-amended soil. Copper in exchangeable and carbonate forms on CK changed remarkably compared with $\mathrm{P}$ - and EP-amended soil, which proved that $\mathrm{P}$ and EP played a certain role in altering the distribution rule of copper forms in the soil column.

\section{Copper accumulation characteristics}

After leaching, the cumulative copper content in the mixed soil samples ranged from 21.70 to $45.88 \mathrm{~g} / \mathrm{kg}$ (Fig. 5). Furthermore, the copper content showed a trend of JL $>\mathrm{SN}>\mathrm{MY}>\mathrm{GA}>\mathrm{DZ}>\mathrm{NB}>\mathrm{GY}>\mathrm{HC}$. The results were consistent with the trend of permeation time, which were contrary to the results of average velocity. Thus, a longer permeation time resulted in stronger copper adsorption and higher copper accumulation content in the soil column. The copper content in different soil samples showed a trend of EP-amended $>$ P-amended $>$ CK. The results demonstrated that the addition of $\mathrm{P}$ could enhance the ability of soil to accumulate copper. The main reason is that this addition increases the content of organic matter in the soil, thus enhancing the complexation of copper ions in the soil samples. Compared with P, EP-amended soil has stronger adsorption 
capacity for copper. This characteristic may be due to the increase in porosity and specific surface area of soil by the added material of $\mathrm{P}$ and EP, which provides a powerful condition for the adsorption of copper ions (Zhang \& Zhan, 2012; Hu et al., 2016); In addition, EP can form metal complexes with heavy metals, which ultimately enhances the adsorption capacity of copper. The proportions of different copper forms in the soil samples varied. Among them, the carbonate form accounted for the highest at $46.01 \%$, followed by the exchangeable form accounting for $25.96 \%$ and then the iron-manganese oxide form $(16.52 \%)$. Finally, the organic matter form (11.51\%) was relatively small. This proportion was mainly related to a higher amount of carbonates in the soil sample and the ability to exchange ions.

\section{DISCUSSIONS}

\section{Correlation between soil physicochemical properties and $\mathrm{Cu}$ froms}

Soil $\mathrm{pH}, \mathrm{CEC}$, total organic carbon (TOC), and specific surface area have important effects on the chemical forms of copper, as shown in Fig 6. On the one hand, the results showed that the CEC of soil was significantly correlated with the contents of exchangeable copper and carbonate copper in different soils. Moreover, the clay content had a significant correlation with exchangeable copper. On the other hand, the correlation between $\mathrm{pH}$ and specific surface area and various forms of copper content in soil was non-significant. The results showed that CEC had a great influence on the copper content in soil samples, and $\mathrm{pH}$ and specific surface area had little impact on the copper in the samples. The above results were mainly because of CEC, which could provide the number of adsorption sites on the soil surface. The larger number of adsorption sites, the stronger the ions in the exchangeable form were ( $\mathrm{Lu}$ et al., 2014). TOC and copper contents in the soil sample were negatively correlated. The TOC content in the soil sample occupied the adsorption point of the tested soil, thus inhibiting the adsorption capacity of the tested soil to copper (Teng et al., 2007)

\section{Difference in copper adsorption}

Our results showed the variations of copper adsorption on different tested soils (Fig. 7). The absorption of copper by natural soil depended on the physical and chemical properties of soil and clay content. The adsorption capacity of clay for copper mainly depended on the negative charge adsorption point between layers (Cui et al., 2010). However, the adsorption capacity of the original soil for copper was low because of their low clay content. 
214 P was mainly composed of cellulose, hemicellulose, and pectin. Research demonstrated that the metal adsorption

215 affinity of P mainly came from the surface bonding of cellulose and complexing action of pectin (Mykola et al.,

216 1999). Therefore, P-amended soil in this study had higher copper binding capacity than the original soil. After

217 modification by EDTA, the effective functional groups on P were increased, and the morphology was more

218 porous (Qi, 2012). Meanwhile, EDTA was able to form stable complexes with most heavy metal ions (Zhang et

219 al., 2018; $L i, 2014$ ), and improve the adsorption capacity of EP-amended soil samples for copper.

220

221

222

223

224

225

226

227

228

229

230

231

232

233

234

235

236

237

238

239

240

\section{CONCLUSION}

This study showed several key points, which described the effectiveness of amendments on the immobilization of heavy metals. The permeation time of copper in each soil column showed EP-amended $>$ Pamended $>$ original soil. In addition, it presented $\mathrm{JL}>\mathrm{SN}>\mathrm{MY}>\mathrm{GA}>\mathrm{DZ}>\mathrm{NB}>\mathrm{GY}>\mathrm{HC}$ at different locations. The average velocity of copper on each soil column indicated a reverse trend with the permeation time. In the vertical distribution, copper contents in exchangeable, carbonate, and iron-manganese oxide forms decreased with the increase of soil column depth, among which the carbonate form decreased most evidently. Copper accumulation at various locations and on different soils presented the same trend with permeation time. The largest proportion was the carbonate form, followed by the exchangeable and iron-manganese oxide forms. The organic matter form was the lowest. A significant correlation was observed between the CEC and the exchangeable and carbonate forms of copper. Meanwhile, TOC and copper contents were negatively correlated.

\section{ACKNOWLEDGEMENTS}

The authors wish to acknowledge and thank the Fundamental Research Funds of China West Normal University (17E062), the Scientific Research Fundation of the Education Department of Sichuan Province (18ZB0576), the Sichuan Province Science and Technology Support Program (2018JY0224) and the National Natural Science Foundation of P.R. China (41271244).

\section{CONFLICT OF INTRESTS}

The authors declare that they have no conflict of interest.

\section{REFERENCE}

Ari V, Anne K. 2005. Ultrasound-assisted sequential extraction method for the evaluation of mobility of toxic elements in contaminated soils. International Journal of Environmental Analytical Chemistry 85:1037-1049 
241

242

243

244

245

246

247

248

249

250

251

252

253

254

255

256

257

258

259

260

261

262

263

264

265

266

267

268

269

270

271

272

273

274

275

276

DOI 10.1080/03067310500138992.

Arias M, Paradelo M, López E, Simal-Gándara, J. 2006. Influence of $\mathrm{pH}$ and soil copper on adsorption of metalaxyl and penconazole by the surface layer of vineyard soils. Journal of agricultural and food chemistry 54:8155-62 DOI 10.1021/jf061526r.

Bes C, Mench M. 2008. Remediation of copper-contaminated topsoils from a wood treatment facility using in situ stabilisation. Environmental Pollution 156:1128-1138 DOI 10.1016/j.envpol.2008.04.006.

Christian H, Manfred R, Mieczyslaw H, Zofia S, Grzegorz J, Bernd M. 1999. Reactions of sewage farm soils to different irrigation solutions in a column experiment. 1. Solid phase physicochemical properties. Journal of Plant Nutrition and Soil Science 162:653-659 DOI 10.1002/(SICI)1522-2624(199912)162.

Cui DS, Xiang W, Cao LJ, Liu QB. 2010. Experimental study on reducing thickness of adsorbed water layer for red clay particles treated by ionic soil stabilizer. Chinese Journal of Geotechnical Engineering 32(06):944949 DOI CNKI:SUN:YTGC.0.2010-06-026.

Fereydoun G, Abdolhossien P, Abbasali Z, Behzad T. 2015. Assessment of heavy metal pollution in water and sediments from the ghalechay river, baychebagh copper mine area, Iran. Soil and Sediment Contamination: An International Journal 24(2):172-190 DOI 10.1080/15320383.2014.937391.

Hao HY, Niu ML, Wang Y, Fan YL, Sun LH. 2016. Extraction of total flavonoids from purslane using ethanolammonium sulfate aqueous two phase system. Journal of Anhui Agricultural Sciences 44(11):145-147 DOI 10.3969/j.issn.0517-6611.2016.11.048 [in chinese].

Hu MM, An Y, Xu MF. 2016. Study on Fruit Peel Adsorbent Application to Removal ofHeavy Metal lons. Guangzhou Chemical Industry 44:12-14+40 [in chinese].

Hu PJ, Yang BF, Dong CX, Chen LK, Cao XY, Zhao J, Wu LH, Luo YM, Peter C. 2014. Assessment of EDTA heap leaching of an agricultural soil highly contaminated with heavy metals. Chemosphere 117:532-537 DOI 10.1016/j.chemosphere.2014.08.081.

Li HX, Lei J, Liu Q, Wang JB, He CR, He JM, Mao HY. 2011. Study on the processing technique of dietary fiber from lemon pomace. Science and Technology of Food Industry 287-290 DOI CNKI:SUN:SPKJ.0.201109-070.

Li LJ, Zhang Q, Bai GJ, Liu P, Ding YJ, Nie D, Wu WL. 2012. Effect of three amendments on cole yield and cole's absorbing heavy metals. Journal of soil and water conservation 26:154-159 DOI 10.13870/j.cnki.stbcxb.2012.05.006.

Li W, Zhu J. 2019. Thoughts on the Transformation and Upgrading of Lemon Industry in Anyue County. Science and technology of sichuan agriculture 67-69 [in chinese].

Li WB, Zhu L, Deng HY, Zhang YF, Xie J, Chen XY, Li T, Meng ZF. 2020. Effect of Biochar Application on Adsorption of Copper by Riverbank Soils. Earth and Environment 48:250-257 DOI 10.14050/j.cnki.16729250.2020.01.017 [in chinese].

Li YZ. 2014. Modification of granular activated carbon and treatment of wasterwater containning EDTA in the three-dimensional electrode reactor. Central South University.

Peer) reviewing PDF | (2020:10:53356:3:1:NEW 14 May 2021) 
277 Lu T, Wang XQ, Ma YB. 2014. Study on the ecological safety threshold of copper in agricultural sludge.

278

279

280

281

282

283

284

285

286

287

288

289

290

291

292

293

294

295

296

297

298

299

300

301

302

303

304

305

306

307

308

309

310

311

312

Journal of Ecotoxicology 9(04):715-728 DOI 10.7524/AJE.1673-5897.20140510003.

Malandrino M, Abollino O, Buoso S, Giacomino A, La GC, Mentasti E. 2011. Accumulation of heavy metals from contaminated soil to plants and evaluation of soil remediation by vermiculite. Chemosphere 82(2):169-78 DOI 10.1016/j.chemosphere.2010.10.028.

Mao MC, Liu C, Cao J, Liu BK, Zhang ZD. 2019. Adsorption characteristics and mechanism of two kinds of wood bio-carbon on $\mathrm{Cu}$ ions. Environment and Development 31(01): 103-105 DOI 10.16647/j.cnki.cn151369/X.2019.01.058.

Mohammad KU. 2017. A review on the adsorption of heavy metals by clay minerals, with special focus on the past decade. Chemical Engineering Journal 308:438-462 DOI 10.1016/j.cej.2016.09.029.

Mykola TK, Lidiya AK, Batyr KV. 1999. Evaluation of pectin binding of heavy metal ions in aqueous solutions. Chemosphere 38(11):2591-2596 DOI 10.1016/S0045-6535(98)00466-4.

Papassiopi N, Tambouris S, Kontopoulos A. 1999. Removal of heavy metals from calcareous contaminated soils by EDTA leaching. Water Air and Soil Pollution 109(1-4):1-15 DOI 10.1023/A:1005089515217.

Parajuli D, Kawakita H, Kajiyama K, Ohto K, Harada H, Inoue K. 2008. Recovery of gold from hydrochloric acid by using lemon peel gel. Separation Science and Technology 43(9-10), 2363-2374 DOI 10.1080/01496390802148472.

Pérez MR, Pavlovic I, Barriga C, Cornejo J, Hermosín MC, Ulibarri MA. 2006. Uptake of $\mathrm{Cu}^{2+}$, $\mathrm{Cd}^{2+}$ and $\mathrm{Pb}^{2+}$ on $\mathrm{Zn}-\mathrm{Al}$ layered double hydroxide intercalated with edta. Applied Clay Science 32(3-4):245-251 DOI 10.1016/j.clay.2006.01.008.

Perlatti F, Otero XL, Macias F, Ferreira TO. 2014. Geochemical speciation and dynamic of copper in tropical semi-arid soils exposed to metal-bearing mine wastes. Science of the Total Environment 500-501(1):91-102 DOI 0.1016/j.scitotenv.2014.08.086.

Qi YF. 2012. Adsorption behaviors of heavy mentals on modified bagasse. Wuhan Institute of Technology [in chinese].

Qin LH, Zhou XT, Cao YX. 2012. development strategy of agricultural product industry chain in anyue county - taking lemon industry as an example. China Business \& Trade 44-45 DOI 10.3969/j.issn.10055800.2012.01.014 [in chinese].

Radanovi DD, Rychlewska U, Djuran MI, Beata W, Drakovi NS, Gurei DM. 2004. Alkaline earth metal complexes of the edta-type with a six-membered diamine chelate ring: Crystal structures of $\left[\mathrm{Mg}\left(\mathrm{H}_{2} \mathrm{O}\right)_{6}\right][\mathrm{Mg}(1,3-$ pdta $)] \cdot 2 \mathrm{H}_{2} \mathrm{O}$ and $\left[\mathrm{Ca}\left(\mathrm{H}_{2} \mathrm{O}\right)_{3} \mathrm{Ca}(1,3\right.$-pdta $\left.)\left(\mathrm{H}_{2} \mathrm{O}\right)\right] \cdot 2 \mathrm{H}_{2} \mathrm{O}$ : Comparative stereochemistry of edta-type complexes. Polyhedron 23(14):2183-2192 DOI 10.1016/j.poly.2004.05.019.

Reetu S, Ankit Y, Shobhana R, Khageshwar SP, Lesia L, Huber M, Huber M, Warren TC, Pablo MR. 2019. Heavy metal pollution in surface soil of Korba Basin, India. Journal of Hazardous Toxic and Radioactive Waste 23(4):05019004 DOI 10.1061/(ASCE)HZ.2153-5515.0000460.

Silveira ML, Alleoni LRF, O'Connor GA, Chang AC. 2006. Heavy metal sequential extraction methods - a

Peer] reviewing PDF | (2020:10:53356:3:1:NEW 14 May 2021) 
313

314

315

316

317

318

319

320

321

322

323

324

325

326

327

328

329

330

331

332

333

334

335

336

337

338

339

340

341

342

343

344

345

346

347

348

modification for tropical soils. Chemosphere 64(11): 1929-1938 DOI 10.1016/j.chemosphere.2006.01.018

Shen WQ, Lei Y. 2016. Study on adsorption and characterization of $\mathrm{H}_{3} \mathrm{PO}_{4}$ modified lemon slag. Jiangsu Agricultural Science 44(3):376-380 DOI 10.15889/j.issn.1002-1302.2016.03.105 [in chinese].

Shen WQ, Shen ZH. 2012. On extraction of essential oil from lemon peel. Journal of Neijiang Teachers College 27(12):51-53 DOI 10.3969/j.issn.1671-1785.2012.12.014 [in chinese].

Shen WQ, Lei Y, Chen YL. 2017. Study on the adsorption of $\mathrm{Cu}^{2+}, \mathrm{Pb}^{2+}$ and $\mathrm{Cr}^{6+}$ on lemon residues modifed by $\mathrm{NaOH} / \mathrm{KOH}$. New Chemical Materials, 45(11), 189-193.

Shen WQ, Lei Y, Shao PL. 2017. Adsorption properties of lemon residues chemically modifed by $\mathrm{H}_{3} \mathrm{BO}_{3}$ to $\mathrm{Cu}^{2+}, \mathrm{Pb}^{2+}$ and $\mathrm{Cr}^{6+}$. Research of Environmental Sciences 30(01): 152-158 DOI 10.13198/j.issn.10016929.2017.01.21.

Sun B, Zhao FJ, Lombi E, McGrath SP. 2001. Leaching of heavy metals from contaminated soils usin EDTA. Environmental Pollution 113(2):111-120 DOI 10.1016/S0269-7491(00)00176-7.

Tahmineh A, Radzuan J, Ahmad KI, Omeid R. 2013. A comparative study of surfactantadsorption by clay minerals. Journal of Petroleum Science and Engineering 101:21-27 DOI 10.1016/j.petrol.2012.10.002.

Teng YG, Liu J, Cui YF, Wang JS. 2007. The geochemical forms and influencing factors of copper in the soil of Dexing mining area. Mineralogy 27(2):59-63 DOI 10.19719/j.cnki.1001-6872.2007.02.010 [in chinese].

Wang CQ, Wang H, Jiang, XY, Huang R, Cao YJ. 2019. Research advances on adsorption of heavy metals by biochar. Chemical Engineering Progress 38(1):692-706 DOI 10.16085/j.issn.1000-6613.2018-0993.

Wasay SA, Barrington SF, Tokunaga S. 1998. Remediation of Soils Polluted by Heavy Metals using Salts of Organic Acids and Chelating Agents. Environmental Technology Letters 19(4): 369-379 DOI 10.1080/09593331908616692.

Xiong XX, Li YX, Li W, Lin CY, Han W, Yang M. 2010. Copper content in animal manures and potential risk of soil copper pollution with animal manure use in agriculture. Resources, Conservation \& Recycling 54(11):985-990 DOI 10.1016/j.resconrec.2010.02.005.

Fujishiro Y, Ito H, Sato T, Okuwaki A. 1997. Synthesis of monodispersed $\mathrm{LaPO}_{4}$ parti es using the hydrothermal reaction of an $\mathrm{La}(\mathrm{edta})-$ chelate precursor and phosphate ions. Journal of Alloys \& Compounds 252(1):103-109 DOI 10.1016/S0925-8388(96)02612-6.

Yuan HF, Wang G, Xu M, Wei BG, Chang Q. 2019. The performance of $\mathrm{Cu}^{2+}$ and EDTA-Cu removal in aqueous solutions with heavy metal flocculant DTMPAM. Acta Scientiae Circumstantiae 39:3985-3993 DOI 10.13671/j.hjkxxb.2019.0240.

Zhang T, Liu JM, Huang XF, Xia B, Su CY, Luo GF, Xu YW, Wu YX, Mao ZW, Qiu RL. 2013. Chelant extraction of heavy metals from contaminated soils using newselective EDTA derivatives. Journal of Hazardous Materials 262(15):464-471 DOI 10.1016/j.jhazmat.2013.08.069.

Zhang W, Zhan Y. 2012. Study on the effect of biosorbent of agriculturai and forestry waste to adsorb copper ion from weastewater. Journal of Henan Agricultural Sciences 41(9):78-80 DOI 10.15933/j.cnki.10043268.2012.09.006.

Peer) reviewing PDF | (2020:10:53356:3:1:NEW 14 May 2021) 
349 Zhang XM, Pu B, Ou Yang LH, Li J. 2006. Research on extraction of dietary fiber from lemon peel by 350 fermentation with Trichoderma viride and the bleaching technique. China Brewing 154(1):26-29 DOI 351 10.3969/j.issn.0254-5071.2006.01.010 [in chinese].

352 Zhang YN, Xu M, Dong Y, Ai SY, Wu XJ. 2018. Study on the removal effect of heavy metals from soil by 353 compound leaching with EDTA and citric acid. Contemporary Chemical Industry 47(8):1617-1621 DOI 354 10.13840/j.cnki.cn21-1457/tq.2018.08.022.

355 Zhu DW, Wei Y, Zhao YH, Wang QL, Han JC. 2018. Heavy metal pollution and ecological risk assessment 356 of the agriculture soil in Xunyang mining area, Shaanxi Province, northwestern China. Bulletin of environmental 357 contamination and toxicology 101:178-184 DOI 10.1007/s00128-018-2374-9. 


\section{Table $\mathbf{1}$ (on next page)}

Basic physical-chemical properties of the riverbank soils, the sampling points, GY, NB, JL, HC, MY, SN, GA and DZ are short for Guanyuan, Nanbu, Jialing, Hechuan, Mianyang, Suining, Guangan and Dazhou respectively. The same as other tables and figures.

The average values are given. $\mathrm{S}$ oil humidity in the table is divided into four grades: we $\mathrm{t}$ (water content $\geq$ $40 \%$ ), moist ( $40 \%>$ water content $\geq 10 \%$ ), slightly moist ( $10 \%>$ water content $\geq 5 \%$ ), and dry (water content $<5 \%$ ). The number of soil pores is divided into three grades: much (porosity $\geq 60 \%$ ), medium $(60 \%>$ porosity $\geq 30 \%)$, and little (porosity $<30 \%)$. The number of soil roots i s divided into three grades: much (root denesty $\geq 20 \%$ ), medium ( $20 \%>$ root denesty $\geq 5 \%$ ), and little (root porosity $<5 \%$ ). Soil structure is divided into block, granular, flake, nucleus, and so on. The pH value was measured by HQ411D desktop pHmeter of American Hash Company, the CEC ( $c$ ation exchange capacity ) was measured by sodium acetate ammonium acetate method, the SSA ( specific surface area ) was measured by V-Sorb2800P Specific surface area analyzer and the TOC ( $t$ otal organic carbon ) was measured by TOC- VCPH TOC instrument. 


\begin{tabular}{|c|c|c|c|c|c|c|c|c|c|c|c|c|c|}
\hline $\begin{array}{c}\text { Soil } \\
\text { samples }\end{array}$ & $\begin{array}{l}\text { Longitude and } \\
\text { latitude }\end{array}$ & $\begin{array}{l}\text { Altitude } \\
\text { (m) }\end{array}$ & Crop rotation & $\begin{array}{c}\text { Soil } \\
\text { humidity }\end{array}$ & $\begin{array}{c}\text { Soil } \\
\text { porosity }\end{array}$ & $\begin{array}{c}\text { Soil } \\
\text { structure }\end{array}$ & $\begin{array}{c}\text { Root } \\
\text { number }\end{array}$ & $\mathbf{p H}$ & $\begin{array}{c}\text { CEC } \\
(\mathbf{m m o l} / \mathbf{k g})\end{array}$ & $\begin{array}{c}\text { TOC } \\
(\mathrm{g} / \mathrm{kg})\end{array}$ & $\begin{array}{c}\text { SSA } \\
\left(\mathrm{m}^{2} / \mathrm{g}\right)\end{array}$ & $\begin{array}{c}\mathrm{Cu} \\
\text { content } \\
\text { (mg/kg) }\end{array}$ & $\begin{array}{c}\text { Clay } \\
\text { content } \\
(\%) \\
\end{array}$ \\
\hline GY & $\begin{array}{c}\text { E105 } 55^{\prime} 18.94^{\prime \prime} \\
\text { N3 } 1^{\circ} 45^{\prime} 6.12^{\prime \prime}\end{array}$ & 430.3 & Peanu, corn & $\begin{array}{l}\text { slightly } \\
\text { moist }\end{array}$ & much & granular & little & 8.16 & 120.72 & 15.75 & 90.34 & 18.84 & 10.74 \\
\hline NB & 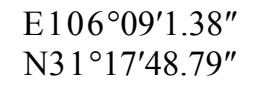 & 427.4 & Chili, rice & $\begin{array}{l}\text { slightly } \\
\text { moist }\end{array}$ & little & blocky & little & 7.99 & 118.22 & 28.16 & 110.44 & 13.80 & 9.22 \\
\hline $\mathbf{J L}$ & $\begin{array}{l}\text { E106 } 06^{\circ} 06^{\prime} 37^{\prime \prime} \\
\text { N30 } 42^{\circ} 19^{\prime \prime}\end{array}$ & 270.0 & $\begin{array}{l}\text { Corn, sweet } \\
\text { potato }\end{array}$ & moist & much & granular & medium & 7.70 & 204.08 & 12.28 & 130.21 & 16.32 & 12.51 \\
\hline $\mathrm{HC}$ & $\begin{array}{l}\mathrm{E} 106^{\circ} 17^{\prime} 30^{\prime \prime} \\
\mathrm{N} 29^{\circ} 58^{\prime} 23^{\prime \prime}\end{array}$ & 245.1 & $\begin{array}{l}\text { Sweet potato, } \\
\text { green beans }\end{array}$ & $\begin{array}{l}\text { slightly } \\
\text { moist }\end{array}$ & little & blocky & little & 6.56 & 100.69 & 25.83 & 89.34 & 24.74 & 7.28 \\
\hline MY & $\begin{array}{l}\mathrm{E} 105^{\circ} 03^{\prime} 25.6^{\prime \prime} \\
\mathrm{N} 31^{\circ} 08^{\prime} 57.43^{\prime \prime}\end{array}$ & 380.7 & Corn, konjac & moist & little & blocky & little & 7.80 & 122.53 & 25.01 & 98.25 & 19.68 & 9.27 \\
\hline SN & $\begin{array}{c}\mathrm{E} 105^{\circ} 38^{\prime} 17^{\prime \prime} \\
\mathrm{N} 30^{\circ} 27^{\prime} 45^{\prime \prime}\end{array}$ & 283.1 & $\begin{array}{l}\text { Corn, } \\
\text { pterocarpus }\end{array}$ & moist & little & blocky & much & 7.44 & 182.79 & 8.84 & 103.14 & 8.75 & 10.66 \\
\hline DZ & $\begin{array}{c}\text { E106 } 06^{\circ} 57^{\prime} 20.07^{\prime \prime} \\
\text { N30 } 51^{\prime} 38.5^{\prime \prime}\end{array}$ & 314.0 & Corn, rice & $\begin{array}{l}\text { slightly } \\
\text { moist }\end{array}$ & little & granular & little & 7.42 & 118.31 & 24.23 & 141.27 & 23.04 & 9.41 \\
\hline GA & $\begin{array}{c}\text { E106 } 106^{\circ} 40^{\prime} 25^{\prime \prime} \\
\text { N302 } 27^{\prime} 42^{\prime \prime}\end{array}$ & 0.0 & $\begin{array}{l}\text { sweet potato, } \\
\text { corn }\end{array}$ & $\begin{array}{l}\text { slightly } \\
\text { moist }\end{array}$ & medium & granular & much & 7.59 & 153.98 & 21.56 & 102.45 & 58.38 & 10.15 \\
\hline
\end{tabular}




\section{Table 2 (on next page)}

Permeation time and average velocity of $\mathrm{Cu}^{2+}$ in different soil columns.

Pomace (P) and ethylene diamine tetra-acetic acid modified P (EP) were added to GY, NB, JL, $H C, M Y, S N, G A$, and DZ with original bank soils as contrast (CK), namely, GY ${ }_{C K}$ (GY soil), GY (GY soil + 1\%P), GY $\mathrm{EP}_{\text {EP }}(\mathrm{GY}$ soil + 1\%EP), and so on . 


\begin{tabular}{cccccccc}
\hline Soil samples & $\begin{array}{c}\text { Permeation } \\
\text { time (h) }\end{array}$ & $\begin{array}{c}\text { Average } \\
\text { velocity (mL/h) }\end{array}$ & Soil samples & $\begin{array}{c}\text { Permeation } \\
\text { time (h) }\end{array}$ & $\begin{array}{c}\text { Average } \\
\text { velocity (mL/h) }\end{array}$ \\
\hline \multirow{4}{*}{$\mathrm{GY}$} & $\mathrm{GY}_{\mathrm{CK}}$ & 80 & 18.0 & & $\mathrm{MY}_{\mathrm{CK}}$ & 128 & 14.1 \\
& $\mathrm{GY}_{\mathrm{P}}$ & 122 & 15.3 & $\mathrm{MY}$ & $\mathrm{MY}_{\mathrm{P}}$ & 156 & 12.8 \\
& $\mathrm{GY}_{\mathrm{EP}}$ & 132 & 13.0 & & $\mathrm{MY}_{\mathrm{EP}}$ & 180 & 11.0 \\
$\mathrm{NB}$ & $\mathrm{NB}_{\mathrm{CK}}$ & 92 & 17.4 & & $\mathrm{SN}_{\mathrm{CK}}$ & 140 & 13.4 \\
& $\mathrm{NB}_{\mathrm{P}}$ & 120 & 14.1 & $\mathrm{SN}$ & $\mathrm{SN}_{\mathrm{P}}$ & 172 & 12.0 \\
& $\mathrm{NB}_{\mathrm{EP}}$ & 144 & 12.5 & & $\mathrm{SN}_{\mathrm{EP}}$ & 192 & 10.3 \\
& $\mathrm{JL}_{\mathrm{CK}}$ & 164 & 12.2 & & $\mathrm{DZ}_{\mathrm{CK}}$ & 108 & 16.4 \\
$\mathrm{JL}$ & $\mathrm{JL}_{\mathrm{P}}$ & 184 & 11.4 & $\mathrm{DZ}$ & $\mathrm{DZ}_{\mathrm{P}}$ & 136 & 13.7 \\
& $\mathrm{JL}_{\mathrm{EP}}$ & 208 & 9.7 & & $\mathrm{DZ}_{\mathrm{EP}}$ & 152 & 11.7 \\
& $\mathrm{HC}_{\mathrm{CK}}$ & 68 & 18.9 & & $\mathrm{GA}_{\mathrm{CK}}$ & 116 & 15.6 \\
$\mathrm{HC}$ & $\mathrm{HC}_{\mathrm{P}}$ & 96 & 16.3 & $\mathrm{GA}$ & $\mathrm{GA}_{\mathrm{P}}$ & 148 & 13.2 \\
& $\mathrm{HC}_{\mathrm{EP}}$ & 122 & 14.3 & & $\mathrm{GA}_{\mathrm{EP}}$ & 164 & 11.1 \\
\hline
\end{tabular}

1 
Figure 1

Distribution map of sampling points. The sampling points are Guangyuan (GY), Nanbu $(\mathrm{NB})$, Jialing (JL), and Hechuan (HC) from the Jialing River; Mianyang (MY) and Suining (SN) from the Fu River; and Guang'an (GA) and Dazhou (DZ) from the Qu River.

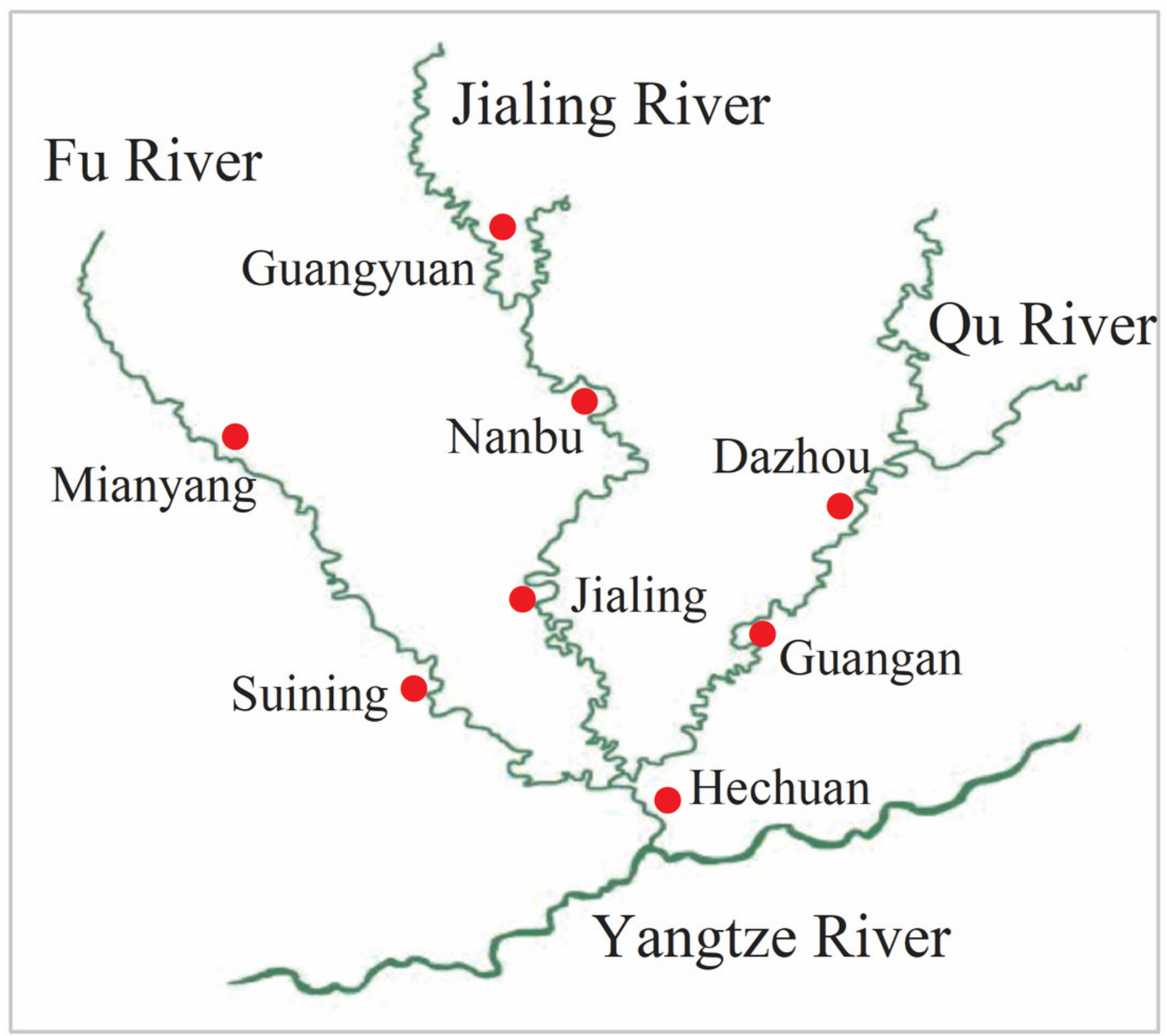


Figure 2

Scheme of the experimental setup

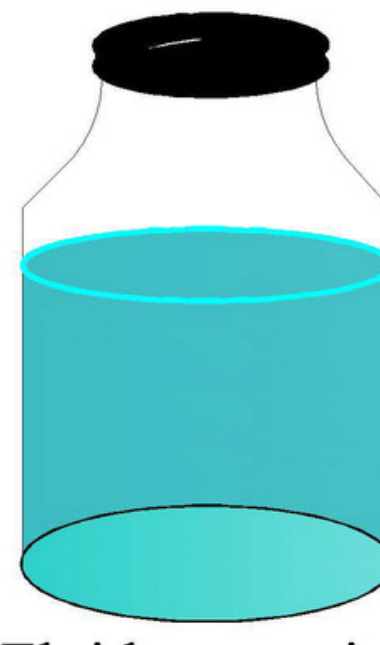

Fluid reservoir
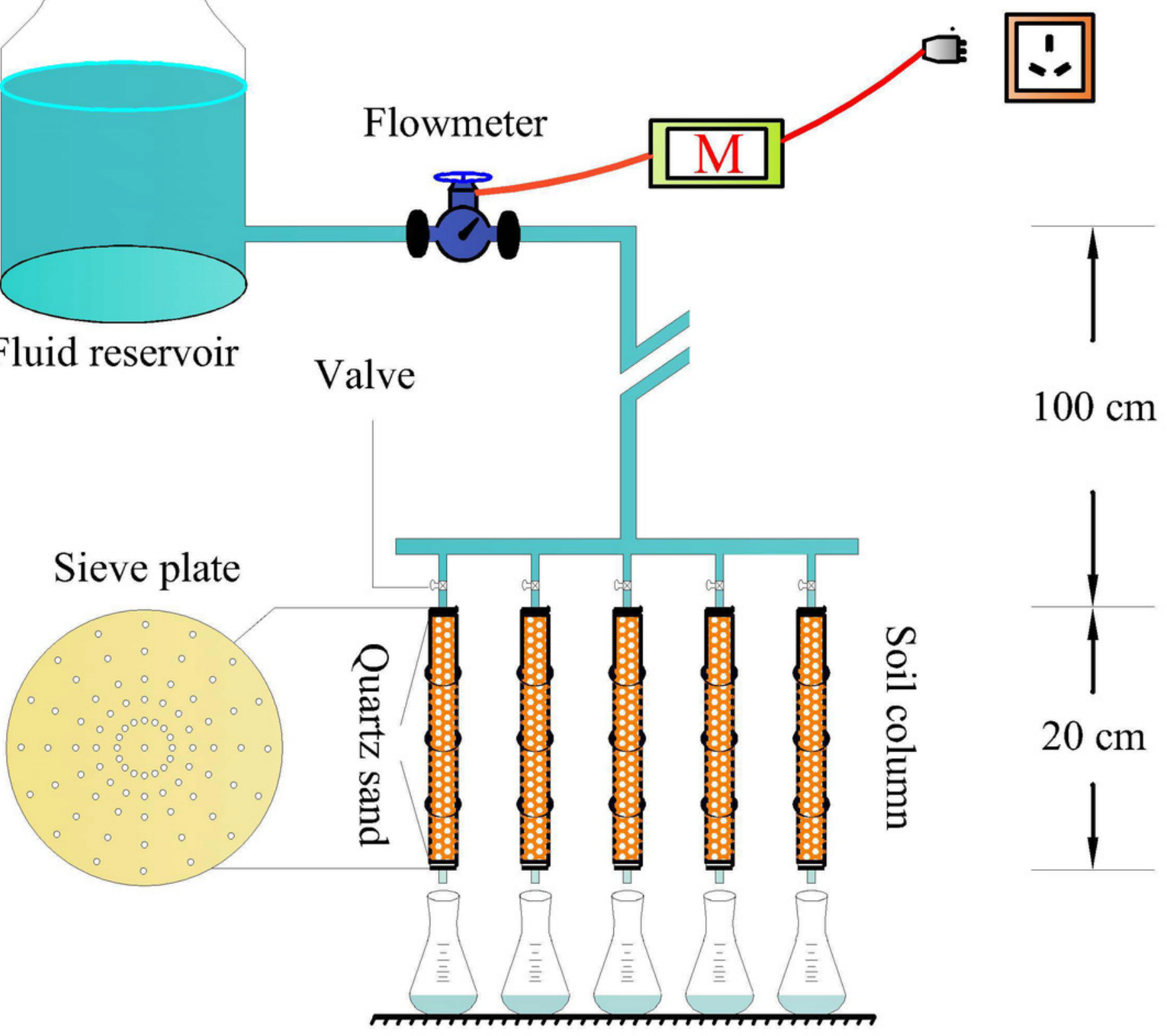
Figure 3

Copper penetration characteristics in the soil columns. CK, P, and EP stand for original, pomace-amended and ethylene diamine tetra-acetic acid modified P-amended soil. The same as other tables and figures.

Fig. $3 \mathrm{~A}-3 \mathrm{H}$ represent the riverbank soils from GY, NB, JL, HC, MY, SN, GA and DZ respectively. 

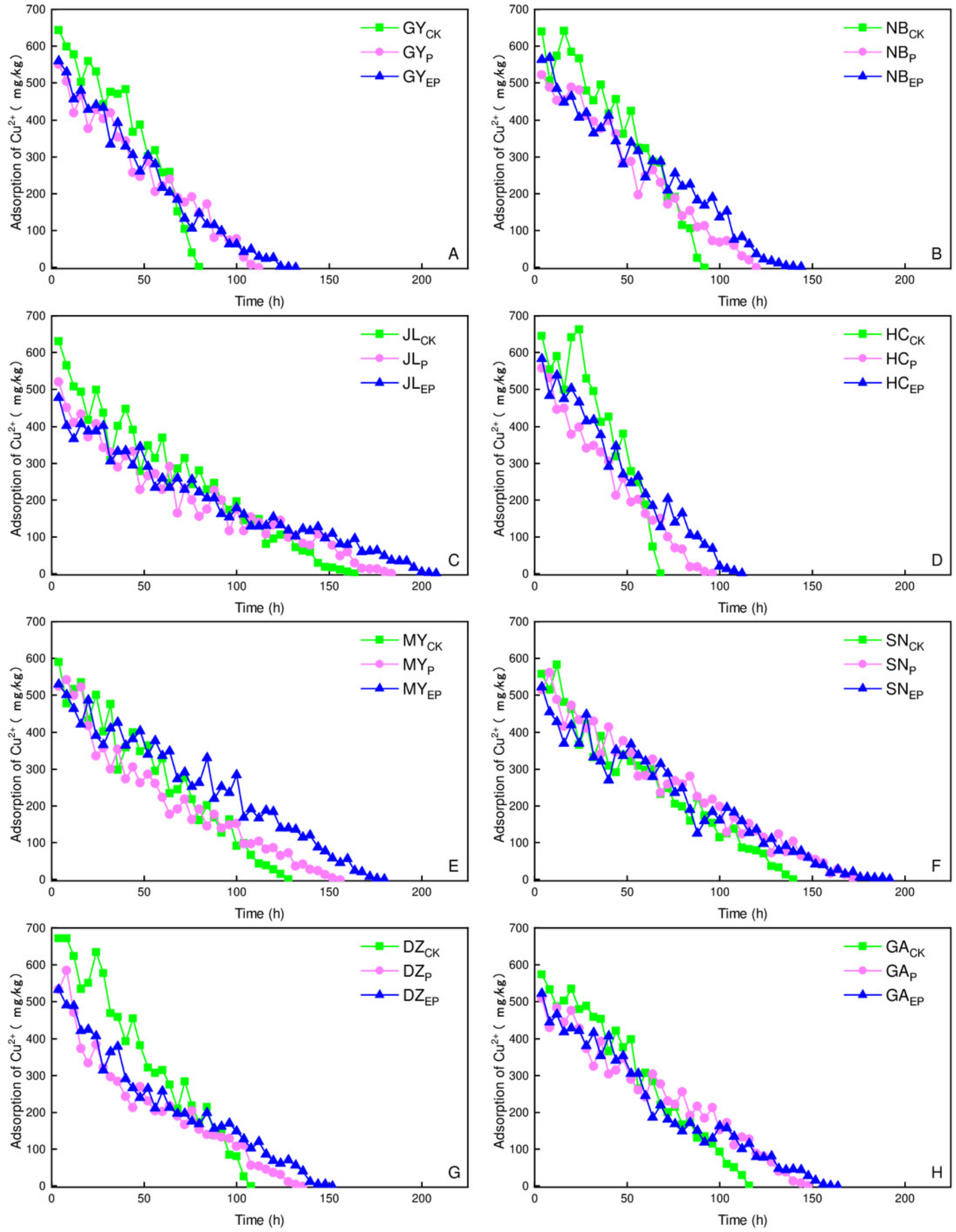
Figure 4

Distribution characteristics of $\mathrm{Cu}$ in different forms in vertical section.

Fig.4A-4C, Fig.4D-4F, Fig.4G-4I, and Fig.4J-4L were exchangeable, carbonate, iron-manganese oxide, and organic matter form respectively. 
Exchangeable form $(\mathrm{g} / \mathrm{kg})$
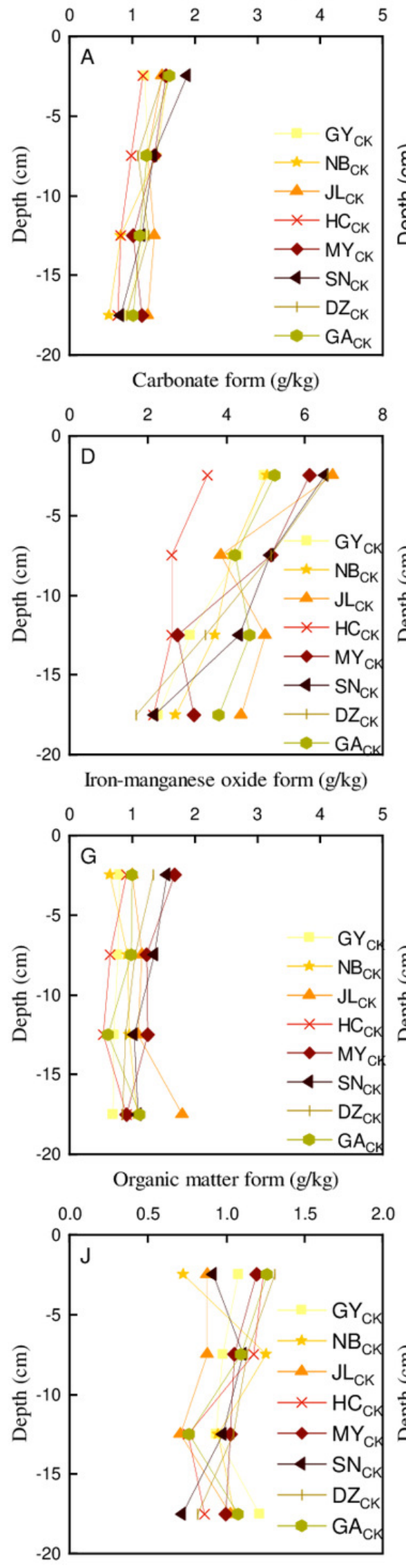

Exchangeable form $(\mathrm{g} / \mathrm{kg})$
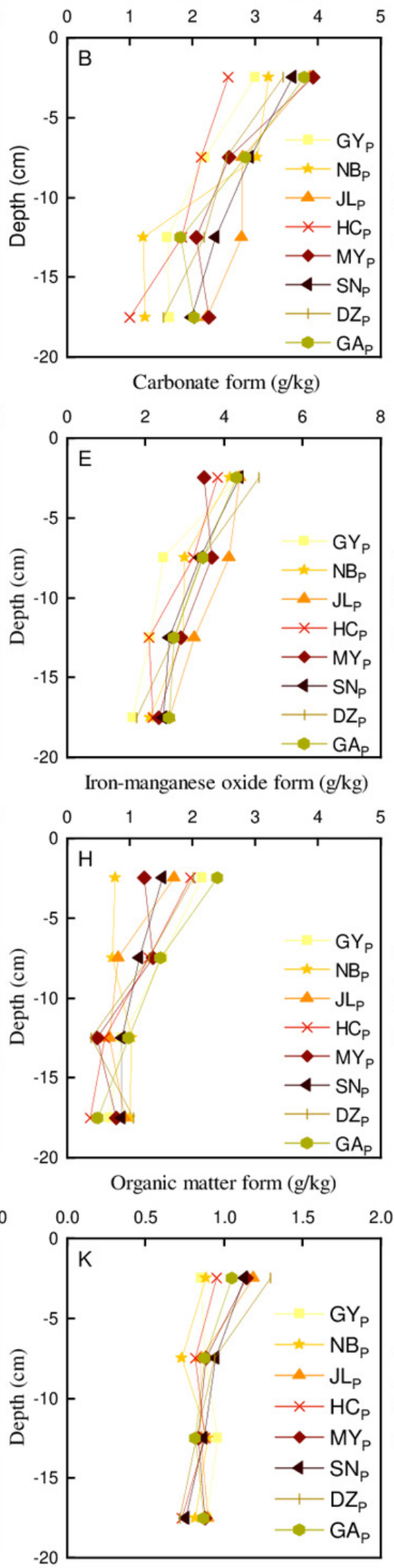

Exchangeable form $(\mathrm{g} / \mathrm{kg})$
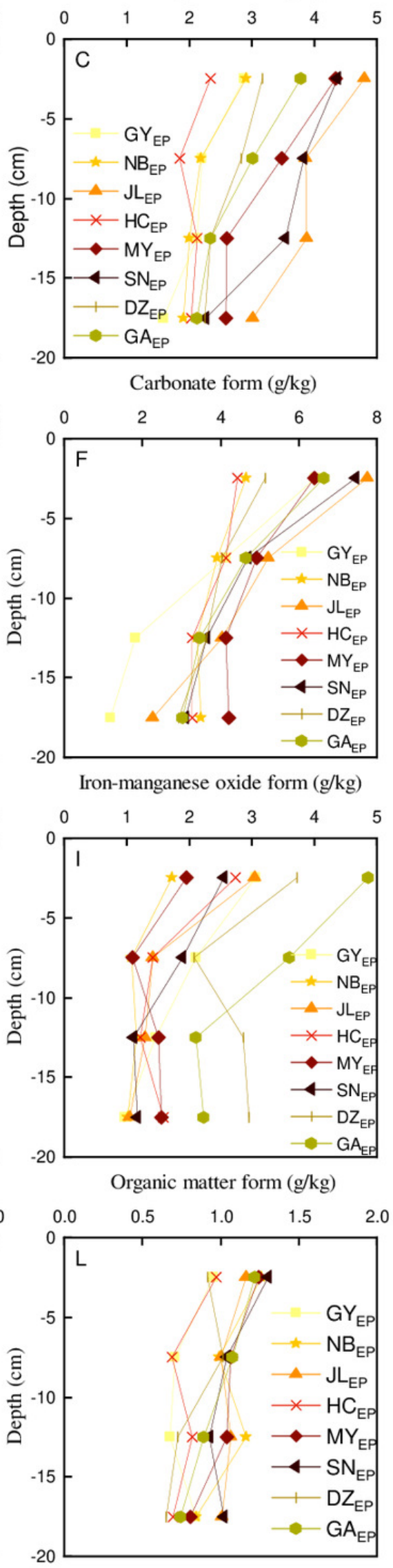
Figure 5

Copper contents (colour changes) in various forms of different riverbank soils from the three rivers.

Fig. 5A-5D, Fig. 5E-5H, and Fig. 5I-5L indicate original, P-amended, and EP-amended soil respectively. 

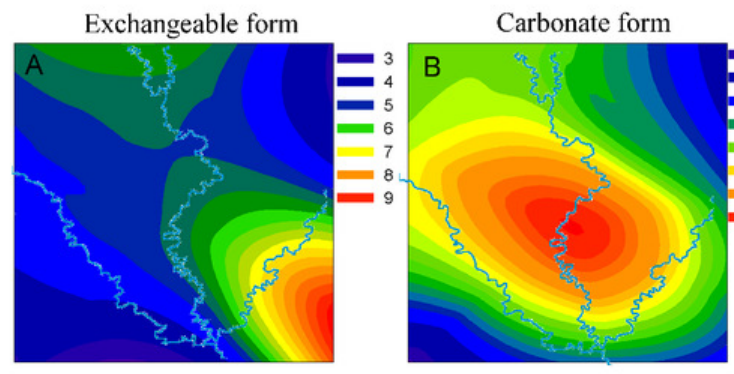

Iron-manganese oxide form
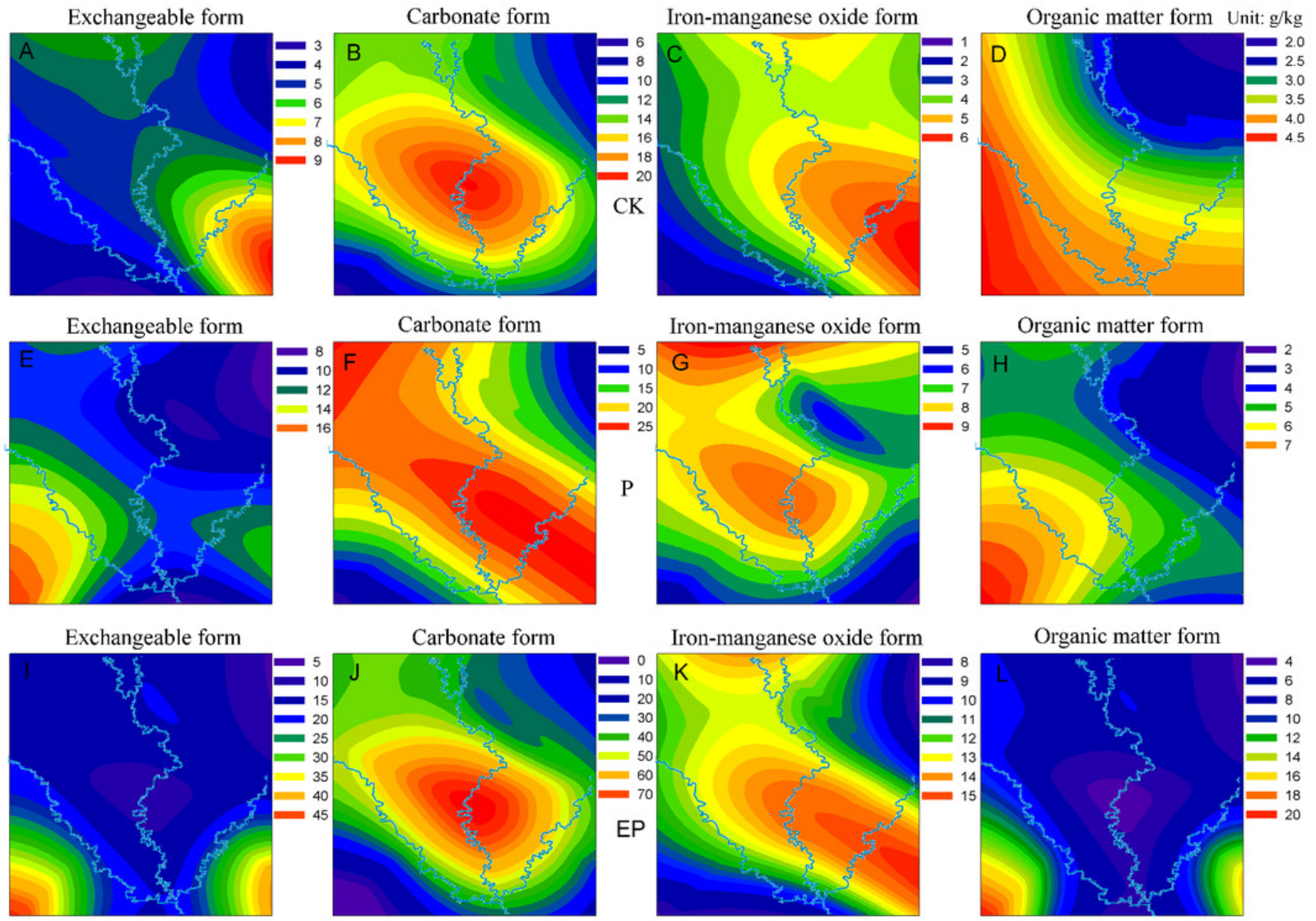

Carbonate form

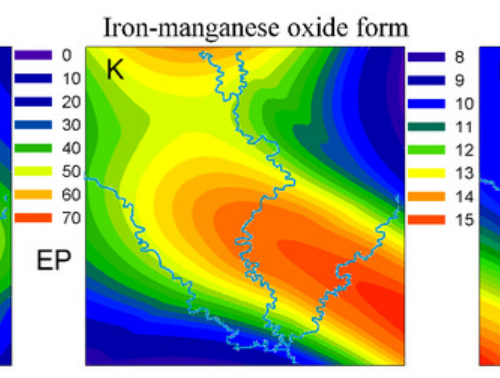

Organic matter form
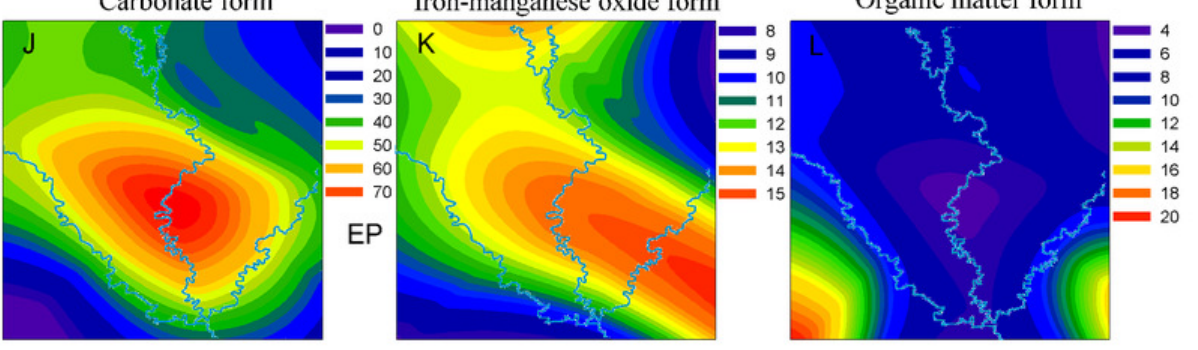


\section{Figure 6}

Correlation analysis of soil physicochemical properties and Cu geochemical characteristics. EX, CA, IMO, OM, and TO are the acronyms for exchangeable, carbonate, iron-manganese oxide, organic matter and total forms of copper, respectively.

Fig. 6A, Fig. 6B, and Fig. $6 \mathrm{C}$ were original, P-amended, and EP-amended soil respectively. * and ** indicate a significant correlation at the level of $p=0.05$ or 0.01 . $(r=0.959$ and $r=0.878$ when the degree of freedom $f$ $=7$ )

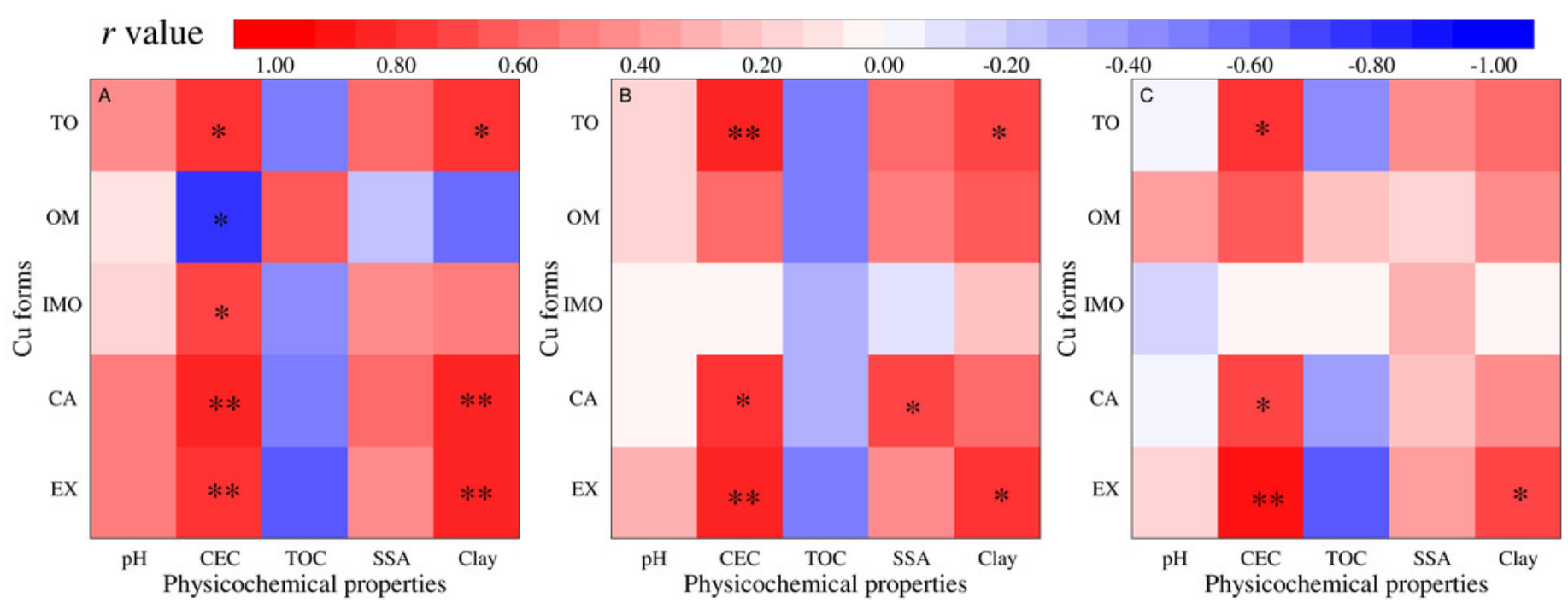




\section{Figure 7}

Adsorption differences of copper on different riverbank soils (original, P-amended, and EP-amended soil). CK is original soil, $\mathrm{P}$ and EP were pomace and ethylene diamine tetraacetic acid modified pomace.

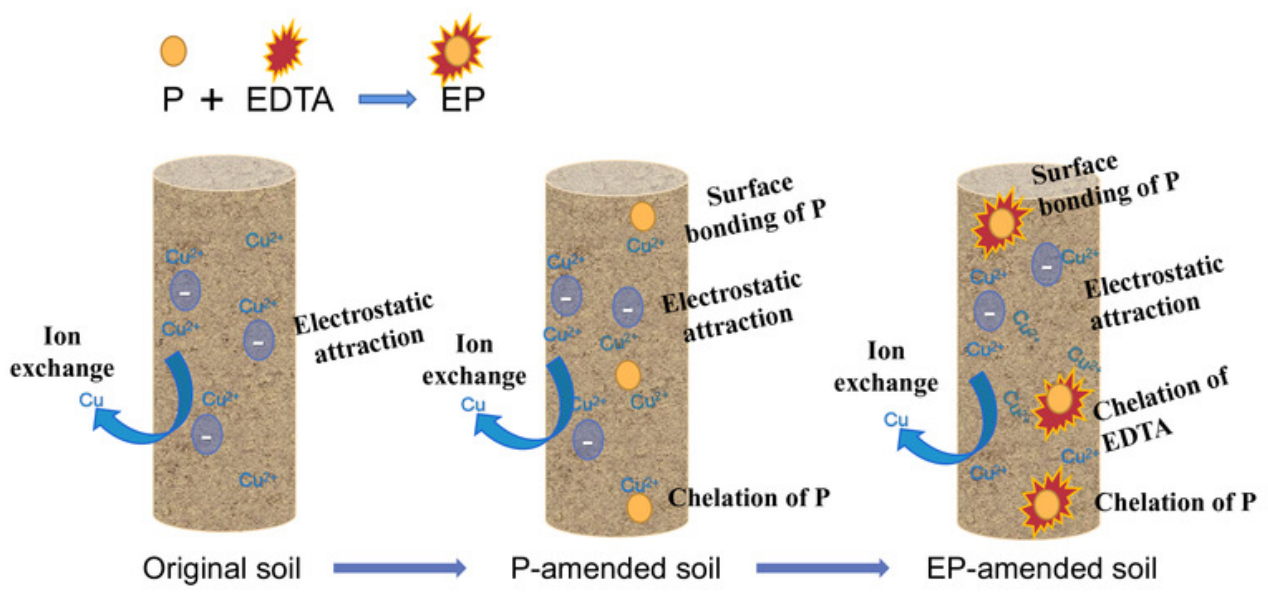

